\title{
Epigenética: mecanismos, herança e implicações no melhoramento animal
}

\author{
Paiva, J.T. ${ }^{1 @ ;}$ Resende, M.D.V. ${ }^{2,3}$; Resende, R.T. ${ }^{2}$; Oliveira, H.R. ${ }^{\text {; }}$ Silva, H.T. ${ }^{\text {; }}$ Caetano, G.C. ${ }^{\text {; }}$ Lopes, P.S. ${ }^{1}$ e Silva, F.F. ${ }^{1}$
}

'Universidade Federal de Viçosa, Departamento de Zootecnia, Viçosa, MG, Brasil.

2Universidade Federal de Viçosa, Departamento de Estatística, Viçosa, MG, Brasil.

${ }^{3}$ Empresa Brasileira de Pesquisa Agropecuária-EMBRAPA Floresta, Colombo, PR, Brasil.

PalaVRas CHAVE ADICIONAIS

Epigenoma.

Expressão gênica.

Metilação.

Histona.

Transgeracional.

\begin{abstract}
RESUMO
A epigenética é definida como mudanças na expressão gênica que podem ser herdadas e que não alteram a sequência do DNA. Existem dois mecanismos epigenéticos principais, a metilação do DNA e a modificação de histonas. Também se destaca o imprinting genômico, - qual está relacionado com a regulação gênica quando apenas um alelo (herdado do pai ou da mãe) se expressa. A herança epigenética transgeracional consiste da herança de marcas epigenéticas através de células germinativas, que controla os padrões de expressão gênica e são passados de uma geração para a outra. Dentro do programa de melhoramento animal é importante avaliar a extensão com que a herança epigenética transgeracional também afeta a eficiência da seleção. Uma melhor compreensão dos mecanismos epigenéticos e seus efeitos transgeracionais no desempenho dos animais poderá permitir maiores ganhos sobre as características de importância econômica.
\end{abstract}

\section{Epigenetics: mechanisms, inheritance and implications in animal breeding}

\section{SUMMARY}

\section{ADDITIONAL KEYWORDS}

Epigenome.

Gene expression.

Methylation.

Histone.

Transgenerational.

INFORMATION

\section{Cronología del artículo.}

Recibido/Received: 23.02 .2017

Aceptado/Accepted: 16.09.2018

On-line: 07.04 .2019

Correspondencia a los autores/Contact e-mail:

teo.paiva@hotmail.com
Epigenetics can be defined as changes in gene expression that can be inherited and do not alter the DNA sequence. There are two main epigenetic mechanisms, DNA methylation and histone modification. Genomic imprinting is a process of gene regulation in which only one allele is expressed. Transgenerational epigenetic inheritance is defined as the inheritance of epigenetic marks through germ cells, which controls the gene expression patterns and are passed down from one generation to another. In the animal breeding program it is important to access the extent that the transgenerational epigenetic inheritance also affects the efficiency of genetic selection. A better understanding of the epigenetic mechanisms and their transgenerational effects on the performance of the animals may allow greater gains in economic important traits.

\section{INTRODUÇÃO}

Grande parte da pesquisa biológica foi guiada com base nas teorias genéticas Mendelianas, assumindo que fenótipos específicos dependem apenas da sequência de bases do DNA. Na área do melhoramento genético animal, tais teorias ainda se fazem presentes nos estudos de avaliação genética (Feeney et al. 2014, p. 48; Goddar \& Whitelaw 2014, p. 247). Recentemente, padrões de herança não-Mendeliana desafiam estas teorias e sugerem a existência de um processo alternativo para explicar certos mecanismos de herança. Assim, a epigenética se revelou como uma área promissora, capaz de demonstrar modificações nos modelos de herança que não envolvem mudanças no DNA (Feeney et al. 2014, p. 48; González-Recio et al. 2015, p. 305; Hu \& Barret 2017, p. 1612; Jablonka \& Raz 2009, p. 131-2). Um fenótipo resulta da interação entre o genoma e o epigenoma, o qual depende do ambiente que o animal foi submetido durante o seu período de 
desenvovimento e a vida adulta (Sinclair et al. 2016, p. 1443-4). Durante o desenvolvimento de um animal, ocorrem alterações químicas nos cromossomos que não alteram a sequência de nucleotídeos, e estas podem ser denominadas de marcas epigenéticas, as quais estão associadas com diversas mudanças na expressão gênica (Heard \& Martienssen 2014, p. 95; Triantaphyllopoulos et al. 2016, p. 31).

A informação genômica de uma célula é bastante estável, enquanto o epigenoma é altamente dinâmico ao longo da vida, sendo governado por uma complexa rede de interação de fatores genéticos e ambientais (Verhoeven et al. 2016, p. 1-3). Normalmente, essas marcas epigenéticas podem ser apagadas e reprogramadas durante a produção de gametas e durante a formação do zigoto, porém, elas também podem persistir no organismo e, por conseguinte, serem herdadas juntamente com o DNA através de gerações (Bernstein et al. 2007, p. 669; Ibeagha-Awemu \& Zhao 2015, p. 302-3; Jablonka \& Raz 2009, p. 132; Skinner 2011, p. 838-9; Szyf 2015, p. 134; Bohacek \& Mansuy 2017, p. 243-4). Diversos fenômenos epigenéticos em animais já foram reportados na literatura (Berghof et al. 2013; Feeney et al. 2014; Frésard et al. 2013; Gao et al. 2017; Leurox et al. 2017; Li et al. 2016; Triantaphyllopoulos et al. 2016) demonstrando a necessidade de compreender plenamente a importância da epigenética na variabilidade fenotípica das características de importância econômica

Poucos trabalhos procuram investigar e quantificar a variância epigenética transgeracional de características utilizadas como critérios de seleção nos programas de melhoramento. Alguns autores vêm propondo modelos estatísticos, incluindo herança epigenética e interações ambientais (Lopes et al. 2015; Johannes \& Colomé-Tatché 2011; Paiva et al. 2018a; Paiva et al. 2018b; Tal et al. 2010; Varona et al. 2015), oferecendo novos caminhos para uma futura inclusão destes mecanismos em estudos de seleção genética. A reversibilidade das modificações epigenéticas, ou seja, a sua natureza potencialmente transitória, poderia constituir um desafio na modelagem de herança. Dentro do programa de melhoramento animal é importante avaliar a extensão com que a herança epigenética transgeracional também afeta a eficiência da seleção genética, uma vez que a epigenética pode ajudar a explicar melhor a variabilidade ambiental e não-Mendeliana de características produtivas e reprodutivas (Frésard et al. 2013, p. 23-4).

Por se tratar de um tema de grande importância na área de melhoramento genético animal, objetivouse abordar conceitos básicos reportados na literatura sobre epigenética e discutir os principais mecanismos epigenéticos conhecidos. A herança epigenética transgeracional será enfatizada tendo em vista suas implicações no melhoramento genético animal.

\section{EPIGENÉTICA - CONCEITO E IMPORTÂNCIA}

A palavra epigenética foi introduzida por Conrad Hal Waddington, derivada da palavra aristotélica epigenesis, do prefixo grego epi, que significa "acima ou sobre algo", combinada com a genética (Waddington 1942). Pode ser definida como mudanças na expressão gênica que são herdadas durante a divisão celular e ao longo das gerações, mas que não alteram a sequência de bases nucleotídicas da molécula de DNA. E ainda, trata-se de marcas que controlam a atividade do genoma e pode ser herdável por mitose ou meiose, não incluindo apenas a expressão gênica, mas também a regulação de elementos transponíveis e o controle da estrutura da cromatina (Bohacek \& Mansuy 2017, p. 243). Os padrões epigenéticos são sensíveis a efeitos ambientais e podem causar mudanças fenotípicas que poderão ser transmitidas aos descendentes (GonzálesRecio 2012, p. 106; Gonzáles-Recio et al. 2015, p.305-7; Verhoeven et al. 2016, p. 1-2).

Os mecanismos epigenéticos apresentam um importante papel para o desenvolvimento normal do organismo e são cruciais para estabelecer a programação correta na expressão dos genes. Durante o desenvolvimento, marcas epigenéticas ocorrem nos cromossomos e estão associadas com os processos de transcrição e tradução gênica. Estas marcas estão envolvidas no desligamento ou ativação de um gene em certos tecidos, em que a sua expressão se faz ou não necessária (lbeagha-Awemu \& Zhao 2015, p. 303; Bohacek \& Mansuy 2017, p. 248). Quando adquirida no início da vida elas podem ter um impacto sobre o fenótipo adulto e podem influenciar nos fenótipos das gerações posteriores por meio de efeitos multigeracionais. As marcas epigenéticas alteram o acesso à informação genética e variam de um tipo celular para outro (Goddard \& Whitelaw 2014, p. 248-9).

Diversos processos biológicos passaram a ser melhor compreendidos após a descoberta dos mecanismos epigenéticos que os controlam. Como exemplo, as fêmeas de abelha desenvolvem-se a partir de larvas geneticamente idênticas, mas a dieta exclusiva com geleia real transforma uma operária infértil em uma rainha fértil, devido a capacidade desse alimento em silenciar um gene chave. A exposição gestacional a determinados nutrientes ou toxinas podem afetar de forma permanente o estado epigenético e a expressão de alguns genes (Kaminen-Ahola et al. 2010; Verhoeven et al. 2016). A redução do cuidado materno logo após o nascimento pode alterar a expressão de um gene, o receptor de glucocorticóides no hipotálamo da prole, resultando em ratos adultos com alta expressão de estress (Weaver et al. 2004, p. 847). Existem dois mecanismos epigenéticos principais: metilação do DNA e modificação de histonas. Os padrões de metilação do DNA são os mais estudados e compreendidos.

\section{PRINCIPAIS MECANISMOS EPIGENÉTICOS}

\section{MetILAÇÃo do DNA}

A metilação do DNA é uma das modificações epigenéticas mais estáveis e conhecidas, além de ser a principal candidata a coordenar a herança epigenética ao longo das gerações. Trata-se de uma marca epigenética herdável e reversível, que é propagada após a replicação do DNA e tem grande influência na expressão gênica (Youngson \& Whitelaw 2008, p. 234; Sinclair et al. 2016, p. 1445). A metilação é essencial para o desenvolvimento embrionário, tendo importante papel na diferenciação celular, inativação do cromossomo 
X e na modificação da cromatina. Consiste na adição de um radical metil na posição $5^{\prime}$ de uma molécula de citosina na sequência do DNA, geralmente seguida por uma guanina (dinucleotídeo $\mathrm{CpG}$ ), onde se encontram os sítios de ligação e reconhecimento destes fatores (Geiman \& Muegge 2010; Suzuki \& Bird 2008, p. 465; Sinclair et al. 2016; p. 1144-5; Triantaphyllopoulos et al. 2016, p. 3).

A regulação da expressão gênica ocorre devido à inibição direta da ligação dos fatores de transcrição em sequencias específicas do DNA. O mecanismo transcricional requer contato com a citosina para que ocorra sua ligação com a dupla hélice do DNA, no entanto, esta ligação torna-se desfavorecida pela metilação das ilhas CpGs (vários elementos curtos de DNA com uma densidade muito mais alta de bases citosinas e guaninas do que qualquer outra região do genoma). Estas regiões altamente metiladas tendem a ser menos transcricionalmente ativas, o que pode ter algum impacto sobre os fenótipos dos animais. A ausência de metilação do DNA proporciona uma cromatina com estrutura aberta facilitadora do início da transcrição (Hemberger et al. 2009; O'Doherty et al. 2015, p. 157-8). Os estados metilados ou não metilados das ilhas CpG são copiados do DNA parental para o DNA do filho e funcionam como uma memória celular. As ilhas $\mathrm{CpG}$ fora das regiões promotoras são mais frequentemente metiladas e leva quase sempre ao silenciamento da transcrição (Strathdee et al. 2008).

\section{MODIFICAÇÃO dE HISTONAS}

As histonas são proteínas nucleares presentes em eucariotos que se associam ao DNA para formar a cromatina. Além de apresentarem função estrutural, também são fundamentais, mediante modificações pós-traducionais, para o controle da expressão gênica, ativação do genoma, metilação do DNA e inativação do cromossomo X. O mecanismo epigenético consiste na ocorrência de modificações nas caudas das histonas e estão associadas a uma maior ou menor compactação da cromatina (Sinclair et al. 2016, p. 1445; Triantaphyllopoulos et al. 2016, p. 3). Quando ocorre uma maior compactação, os sítios de ligação dos fatores de transcrição se tornam inacessíveis e podem também interferir na afinidade de ligação das histonas ao DNA (Zentner \& Henikoff 2013, p. 259).

O perfil de modificação das histonas é regulado por inúmeras enzimas, as quais adicionam e removem modificações covalentes. Histona acetiltransferase e histona metiltransferase adicionam grupos acetil e metil, respectivamente; já as histonas desacetilase e desmetilase atuam removendo esses grupos (Haberland et al. 2009, p. 32). Já foram descritos importantes mecanismos epigenéticos envolvidos nas modificações de histonas, incluindo acetilação, metilação, fosforilação, ubiquitinação, glicosilação, sumoilação, entre outros, o que demonstra a grande complexidade desses mecanismos. A acetilação de histona contribui para o estabelecimento ou a manutenção de um ambiente permissivo à transcrição, embora não necessariamente causando ativação transcricional. Enquanto a desacetilação promove a condensação da cromatina, formando uma barreira para o recrutamento dos fatores de trans- crição (Legube \& Trouche 2003, p. 944-5; Triantaphyllopoulos et al. 2016, p. 2-4).

Existem fortes evidências de que as modificações de histonas são herdadas durante as divisões celulares, porém, essa transmissão é muito mais complexa, principalmente devido à replicação independente das moléculas de histonas (Kim et al. 2009, p. 597). Alguns mecanismos epigenéticos podem ser controlados por efeitos genéticos hereditários e existem genótipos que são mais sensíveis e/ou susceptíveis à metilação do que outros, como é o caso de genótipos com uma maior proporção de citocinas nas ilhas CpG (Gonzáles-Recio et al. 2015, p. 309).

\section{IMPRINTING GENÔMICO}

Para a grande maioria dos genes autossômicos a expressão ocorre a partir dos dois alelos simultaneamente (O’Doherty et al. 2015, p. 156). No entanto, uma pequena proporção foi identificada onde a expressão é restrita a um dos dois cromossomos herdados. Estes genes são ditos "impressos", podendo afetar desdendentes de ambos os sexos, de forma que tais efeitos não surgem como consequência da herança de cromossomos sexuais. O imprinting genômico é um processo de regulação gênica no qual apenas um dos componentes de um par alélico se expressa, dependendo de sua origem parental (Reik \& Walter 2000, p. 21).

De modo geral, os genes maternalmente impressos são transcricionalmente silenciados apenas no cromossomo herdado da mãe, enquanto que genes paternalmente impressos são silenciados no cromossomo herdado do pai (Barlow \& Bartolomei 2014). Nem todos os genes impressos aderem a isso, para alguns genes a repressão transcricional do alelo parental "impresso" é parcial, em que um alelo exibe maiores níveis de expressão em relação ao outro alelo de um mesmo pai de origem, enquanto outros genes impressos exibem padrões específicos que diferem entre indivíduos da mesma espécie (O’Doherty et al. 2015, p. 157-8).

Os genes paternos impressos apresentam o alelo paterno epigeneticamente modificado, prevenindo a transcrição e assegurando a expressão monoalélica do alelo materno, de modo que o mesmo ocorre ao contrário quando os genes maternos são impressos. Por definição, num loci inprintado, apenas um alelo está ativo (materno ou paterno), e o alelo inativo está marcado por alguma mudança epigenética. Os alelos impressos podem ser herdadas por todas as células filhas através da mitose após a fertilização, potencialmente resultando em padrões de expressão gênica impressos durante toda a vida do animal (Morison et al. 2005, p. 457-65). Em bovinos de corte, o imprinting genômico contribui para a variância genética de várias características de importância econômica, com proporções estimadas entre $8 \%$ e $25 \%$ da variância genética aditiva total (Sinclair et al. 2016, p. 1461).

HERANÇA EPIGENÉTICA E MELHORAMENTO ANIMAL

HERANÇA EPIGENÉTICA TRANSGERACIONAL

A herança epigenética transgeracional é caracterizada por modificações ocasionais que ocorrem na 
atividade do gene em células germinativas, de forma que são transferidas para a próxima geração (Bohacek \& Mansuy 2017, p. 243). Ela ocorre entre gerações de organismos que se reproduzem assexuadamente e sexuadamente, afetando diretamente a estrutura hereditária das populações (Jablonka \& Raz 2009, p. 138-9; Szyf 2015, p. 134; Youngson \& Whitelaw 2008; p. 235-7).

A existência de um componente herdável da epigenética é bastante discutida na literatura e dois tipos de herança epigenética são geralmente descritos. A primeira envolve marcas epigenéticas herdadas em linhagem de células somáticas e podem ser conservadas durante a mitose (Jablonka \& Raz 2009, p. 132; Hu \& Barret 2017, p. 1615). A segunda trata-se da herança epigenética transgeracional, em que as marcas são herdadas através da linhagem de células germinativas, que controla os padrões de expressão de genes que são passados de uma geração para a próxima (Bohacek \& Mansuy 2017, p. 243; Daxinger \& Whitelaw 2012, p. 154; Hu \& Barret 2017, p. 1618). Os mecanismos subjacentes à herança epigenética germinativa incluem metilação do DNA, RNAs não codificadores, modificações pós-traducionais das histonas, e possivelmente, outros procesos ainda desconhecidos. As alterações nestas marcas epigenéticas podem ser dependentes ou independentes de mutações genéticas, e além disso, outros fatores como proteínas maternas em oócitos, proteínas priônicas ou microbiotas também podem contribuir para a herança epigenética genermiativa, porém, ainda permanecem sob investigação (Bohacek \& Mansuy 2017, p. 243).

As marcas epigenéticas em mamíferos são deletadas, em geral, durante a meiose. Assim, não são transmitidas à descendência. No entanto, algumas marcas epigenéticas permanecem após este processo de reversão, e podem ocorrer novamente (Heard \& Martienssen 2014, p. 96-7; Rothstein et al. 2017, p. 2). Então, após a fertilização e durante a pré-implantação do embrião, existe uma segunda etapa de deleção destas marcas, uma onda de desmetilação de todo o genoma e logo em seguida, ocorre uma forte onda de metilação, particularmente em linhagens somáticas como estas são estabelecidas, que constitui a reprogramação genética das células no embrião (Frésard et al. 2013, p. 22; Sinclair et al. 2016, p. 1445-6).

As marcas epigenéticas que são herdadas por meiose são instáveis ou metaestáveis, e deletados ao longo de um número de gerações. Se um evento ambiental provoca uma alteração epigenética no animal e se essa mudança é passada para a próxima geração, então a herança de características adquiridas se torna possível (Sinclair et al. 2016; p. 1446). Recomenda-se ter cuidado ao usar o termo "herança epigenética transgeracional". Em um caso específico, por exemplo, o meio ambiente no útero pode ter um efeito duradouro sobre o feto, e parte ou a totalidade deste efeito pode ser mediado por alterações epigenéticas nos cromossomos deste feto, mas esta não é a herança epigenética transgeracional de marcas (Feeney et al. 2014, p. 48-9; Goddard \& Whitelaw 2014, p. 249; Rothstein et al. 2017, p. 2). Existem boas evidências de herança epigenética transgeracional em um pequeno número de casos em mamíferos, enquanto em outras espécies essa evidência se torna mais fraca (Feeney et al. 2014, p. 49; Bohacek \& Mansuy 2017, p. 243).

Através de mecanismos epigenéticos as experiências ambientais maternas podem ser transferidas e influenciarem no desenvolvimento de embriões, podendo afetar os fenótipos da prole e ter consequências funcionais para o comportamento reprodutivo. Além disso, estudos também mostraram herança da metilação do DNA com padrões de transmissão paterna (Rothstein et al. 2017, p. 2-3; Verhoeven et al. 2016, p. 3). A natureza transiente das modificações epigenéticas induzidas pelo ambiente (compartilhadas entre indivíduos replicados) e por modificações aparentemente estocásticas (não compartilhadas entre indivíduos replicados) já são evidenciadas, porém, as variações induzidas pelo ambiente parecem ter uma duração mais curta (Verhoeven et al. 2016, p. 3).

Em um experimento com ratos, Iqbal et al. (2015) mostraram que, embora os desreguladores químicos endócrinos exercem efeitos epigenéticos diretos em células germinais fetais expostas, estas marcas são corrigidas através da reprogramação de eventos e não são transmitidas à descendência. Martínez et al. (2014) reportaram que a desnutrição no útero em ratos resulta em modificações epigenéticas em células germinativas F1, que são posteriormente transmitidos e mantidos em células somáticas da F2. No entanto, a evidência sobre a herança de mais de três gerações ainda precisa ser observada para apoiar a herança epigenética transgeracional (Gonzáles-Recio et al. 2015, p. 308).

\section{Herança ePIGENÉtica transgeracional e aVALIAÇÃo GENÉTICA}

Por meio de um modelo que usa a transmissibilidade epigenética (probabilidade de transmissão de fenótipos ancestrais) e indução ambiental, foi proposto novas expressões para o cálculo das covariâncias entre parentes. Tal et al. (2010) combinaram uma abordagem genética quantitativa clássica com informações sobre o número de oportunidades para ocorrência da reversão epigenética entre gerações e suposições sobre a indução ambiental para estimar a variação epigenética e a transmissibilidade epigenética.

A herança epigenética é geralmente mais simples para modelar do que a herança cultural (características típicas de um grupo social, cultura ou classe que são transmitidas para os seus descendentes), uma vez que normalmente envolve apenas a transmissão vertical, ou seja, de pais para filhos (Gonzáles-Recio et al. 2015, p. 307; Tal et al. 2010, p. 1037). Durante o desenvolvimento, assim como durante a meiose e a gametogênese, alguma parte da informação epigenética dos pais é revertida e reestruturada (Guerrero-Bosagna et al. 2018, p. 2-4). Portanto, é necessário incluir em modelos de herança epigenética o número de gerações que sofreram a reversão, e esse número pode difereir mesmo quando o parentesco genético é o mesmo (Tal et al. 2010, p. 1043).

Para estimar a quantidade de variação epigenética herdável, precisa-se definir alguns conceitos. São eles: variabilidade epigenética herdável, o coeficiente de reversão, e seu complemento, o coeficiente de transmissibilidade 
epigenética. A variabilidade epigenética herdável referese à variabilidade fenotípica que é determinado por marcas epigenéticas que são induzidas ambientalmente e também, possivelmente, herdadas de gerações anteriores. As variações herdáveis em que a herança epigenética depende podem surgir espontaneamente (como um tipo particular de ruído do desenvolvimento), ou podem ser induzidas ambientalmente. Quando as marcas são transmitidas entre gerações, isso vai contribuir para a variabilidade epigenética herdada (Jablonka \& Raz 2009, p. 132; Tal et al. 2010, p. 1038).

$\mathrm{O}$ coeficiente de reversão $(v)$ se refere à probabilidade de mudar o estado epigenético durante a gametogênese e/ou desenvolvimento inicial, para que a nova geração possa responder às atuais condições ambientais com nenhuma memória de ambientes passados. $\mathrm{O}$ complemento deste coeficiente de reversão, $(1-v)$, é o coeficiente de transmissibilidade epigenética, o qual se refere a probabilidade de transmitir o estado epigenético à geração seguinte, sem ocorrer reversão. Este coeficiente deve ser tomado como uma abstração que encapsula todas as potencialidades da herança epigenética relacionada com o fenótipo alvo, através de uma única geração. Enquanto o coeficiente pode ser expresso como uma certa probabilidade, ele também pode ser interpretado como um coeficiente de razão, o qual representa a porção do valor epigenético que é transmitido para a próxima geração. $\mathrm{O}$ modelo também estabelece uma hipótese simplificadora de que o coeficiente de reversão é uma constante da população, embora na realidade pode-se assumir alguma distribuição para ele (Tal et al. 2010, p. 1038-9; Varona et al. 2015, p. 477).

O valor epigenético de um filho depende se seu estado epigenético foi revertido, e em caso de reversão, a contribuição epigenética é determinada pelo ambiente indutor. Os descendentes apresentam reversão do seu estado epigenético com probabilidade $v$ e herda de seus pais o estado epigenético com probabilidade 1 v. $\mathrm{O}$ ambiente indutor pode ser uma exposição a um sinal ou estresse ambiental, e alternativamente, pode ser uma mutação que tem efeitos durante o desenvolvimento do animal e que persiste depois da própria mutação ter sido segregada à distância (Tal et al. 2010, p. 1038).

Pesquisas que buscam estimar a herança epigenética transgeracional ainda são muito limitadas. Até o momento, três estudos utilizando abordagem quantitativa para estimar a variabilidade epigenética transgeracional foram realizados. Varona et al. (2015) avaliaram o procedimento proposto considerando dados simulados e reais, e por meio da redefinição da covariância entre parentes, proposta por Tal et al. (2010, p. 1042) incluíram o efeito epigenético transgeracional no modelo e estimaram os componentes de variância. Os autores reportaram herdabilidade epigenética baixa $(0,036)$ para peso ao nascimento em bovinos de corte e observaram que o modelo com a não inclusão do efeito epigenético era o mais plausível a ser utilizado.

Considerando uma abordagem similar, Paiva et al. (2018a) avaliaram também o efeito epigenético trans- geracional utilizando informações genealógicas e fenotípicas baseado na metodologia de modelos mistos, em uma linhagem de codornas de corte. Os autores observaram que o peso corporal aos sete dias de idade apresentou variação epigenética transgeracional, com herdabilidade epigenética de 0,10, enquanto para os subsequentes pesos corporais foi observado pouca ou quase nenhuma variação epigenética. E ainda, ao avaliarem características de qualidade do ovo em codornas de corte, Paiva et al. (2018b) observaram que o efeito epigenético não foi significativo e reportaram herdabilidades epigenéticas baixas e próximas de zero (variando de 0,00 a 0,07 ).

De acordo com Varona et al. (2017, p. 482-3), o modelo proposto utiliza uma definição básica de herança epigenética transgeracional, pois assume a mesma variância epigenética para todos os indivíduos da população. No entanto, quando os registros fenotípicos são coletados ao longo da vida do indivíduo, os autores sugerem que a variância epigenética transgeracional pode ser modelada como dependente da idade.

Um outro estudo considerando o efeito do imprinting e utilizando o modelo misto tradicional foi proposto por Lopes et al. (2015). Ao trabalhar com suínos da raça Landrace, Large White e Pietrain, os autores reportaram que a proporção de variância fenotípica para as características número de tetas, espessura de toucinho e ganho de peso diário, explicada pelos efeitos do imprinting foram baixas, variando de 0,010 a 0,015, 0,017 a 0,029 e 0,011 a 0,019, respectivamente, para as três raças avaliadas. Ainda, de acordo com os autores, quando os efeitos de dominância e do imprinting foram adicionados ao modelo, a herdabilidade no sentido amplo aumentou para todas as características, nas três populações de suínos.

Goddard and Whitelaw (2014, p. 250) sugerem que a matriz A poderia ser modificada para contabilizar a herança citoplasmática, os genes ligados ao sexo, o imprinting ou a variância não-aditiva devido à dominância e epistasia. Porém, embora esses fenômenos já sejam reconhecidos, nenhum deles estão incluídos no sistema de avaliação genética de rotina. Possivelmente, devido a dificuldade de estimação, uma vez que a variância que eles explicam parece ser pequena, e os efeitos podem ser confundidos com outros, tais como os efeitos de ambiente materno.

Os programas de acasalamento poderiam ser praticados considerando o estado de imprinting dos progenitores para acomodar o estado epigenético mais favorável a complementar o valor genético (González-Recio et al. 2012, p. 109). As estratégias de acasalamento para aumentar determinadas frequências epigenotípicas só são válidas se as marcas epigenéticas forem herdáveis (González-Recio et al. 2015, p. 310) e se a variação epigenética for suficientemente grande, a seleção em linhas macho e fêmea poderia ser feita separadamente (Goddard \& Whitelaw 2014, p. 251).

A implementação prática deve ser cuidadosamente avaliada para incorporar com sucesso as informações epigenéticas na pecuária. Diferente do material genético (DNA), a metilação não é constante durante a vida do indivíduo, e as forças ambientais modelam a meti- 
lação ao longo do tempo. Estudos longitudinais criam um cenário interessante para detectar quais práticas de alimentação e manejo mudam os padrões de metilação, e tais estudos poderiam ajudar a ter conhecimento sobre os fatores que influenciam a metilação e a diferenciar entre a variação epigenética causal e consequente (González-Recio et al. 2012, p. 109; Triantaphyllopoulos et al. 2016, p. 13-4). A herança epigenética dependente da linhagem germinativa é um campo extremamente dinâmico e pesquisas futuras precisarão identificar epimodificações germinativas específicas responsáveis pela transferência de informações para a prole. Por meio de avanços tecnológicos na edição do (epi) genoma, poderão avaliar o seu envolvimento funcional na expressão de características ao longo das gerações. Além disso, será importante também determinar a contribuição de fatores genéticos para a herança epigenética, delineando a interação entre mutação genética e epimodificações (Bohacek \& Mansuy 2017, p. 248).

Em estudos futuros, aliado aos trabalhos quantitativos descritos anteriormente, as análises epigenéticas moleculares serão de grande importância para auxiliar no entendimento mais amplo sobre os efeitos epigenéticos na expressão das características de interesse econômico na produção animal (Guerrero-Bosagna et al. 2018, p. 5). Tal como mencionado por Jablonka and Raz (2009) e Tal et al. (2010), a epigenética pode ser vista como um conceito mais amplo, que pode incluir vários tipos de transmissão cultural. Portanto, a melhoria da produtividade animal tem sido alcançada ao longo dos anos através de programas cuidadosos de criação e seleção. Hoje, variações no genoma estão ganhando importância crescente em estratégias de melhoramento animal. A informação genômica por si só, no entanto, explica apenas uma parte da variância fenotípica nos traços. É provável que uma porção da variância inexplicada esteja embutida no epigenoma. O epigenoma engloba marcas epigenéticas tais como metilação do DNA, modificações da cauda da histona, remodelação da cromatina e outras moléculas que podem transmitir informações epigenéticas, tais como espécies de RNA não codificantes. Os fatores epigenéticos respondem a fatores ambientais externas ou internas, como nutrição, patógenos e clima, e têm a capacidade de alterar a expressão gênica levando ao surgimento de fenótipos específicos. Evidências acumuladas mostram que as marcas epigenéticas influenciam a expressão gênica eo resultado fenotípico em animais de produção. Esta revisão examina evidências disponíveis sobre a influência de marcas epigenéticas nas características de animais de produção (gado, ovelha, cabra e porco) e discute o potencial de consideração de marcadores epigenéticos em programas de melhoramento genético. No entanto, as atividades de investigação epigenética sobre as espécies de animais de produção são atualmente limitadas em parte devido à falta de reconhecimento, financiamento e uma rede global de investigadores. Elucidar, portanto, os determinantes epigenéticos de doenças animais e características complexos pode representar um dos principais desafios para usar marcadores epigenéticos para a melhoria da produtividade animal e não há dúvida de que a regulação epigenética poderia ter profundas implicações na expressão de características de importância econômica dentro dos programas de melhoramento animal. De acordo com Jammes et al. (2010, p. 71), ao considerar a regulação epigenética nas avaliações genéticas poderia impactar de duas maneiras: removendo o viés epigenético na predição do verdadeiro valor genético do animal e aumentando a precisão ao considerar uma fonte de variação fenotípica, o que reduziria o número de progênies e progenitores necessários para se ter estimativas confiáveis do verdadeiro valor genético.

\section{CONSIDERAÇÕES FINAIS}

A epigenética se tornou um campo de pesquisa instigante e desafiador devido à sua grande importância no controle da expressão gênica e no processo evolutivo dos organismos. Este tema vem despertando o interesse de muitos pesquisadores, especialmente geneticistas e melhoristas, por apresentar mecanismos de alta complexidade exercendo influência na expressão dos fenótipos. Contrariando as leis Mendelianas, a epigenética tem potencial para causar mudanças fenotípicas individuais ocasianadas por marcas epigenéticas induzidas pelo ambiente e capazes de serem herdadas ao longo das gerações. Apesar de tudo, a estabilidade e a durabilidade deste tipo de herança ainda parecem ser desconhecidas. Uma melhor compreensão dos mecanismos epigenéticos e seus efeitos transgeracionais no desempenho dos animais poderá permitir maiores ganhos genéticos sobre as características de importância econômica no sistema de produção.

\section{AGRADECIMENTO}

À FAPEMIG, CAPES e ao CNPq, pela concessão das bolsas de pesquisa.

\section{BIBLIOGRAFIA}

Barlow, DP \& Bartolomei, MS 2014, 'Genomic imprinting in mammals', Cold Spring Harbor Perspectives in Biology, vol. 6, no. 2. doi: 10.1101/cshperspect.a018382.

Berghof, TVL, Parmentier, HK \& Lammers, A 2013, 'Transgenerational epigenetic effects on innate immunity in broilers: An underestimated field to be explored?', Poultry Science, vol. 92, no. 11, pp. 29042913. doi: 10.3382/ps.2013-03177.

Bernstein, BE, Meissner, A \& Lander, ES 2007, 'The mammalian epigenome', Cell, vol. 128, no. 4, pp. 669-681. doi: 10.1016/j. cell.2007.01.033.

Bohacek, J \& Mansuy, IM 2017, 'A guide to designing germline-dependent epigenetic inheritance experiments in mammals, Nature Methods, vol. 14, no. 3, pp. 243-249. doi: 10.1093/eep/dvy008.

Daxinger, L \& Whitelaw, E 2012, 'Understanding transgenerational epigenetic inheritance via the gametes in mammals', Nature Reviews Genetics, vol. 13, no. 3, pp. 153-162. doi: 10.1038/nrg3188.

Feeney, A, Nilsson, E, \& Skinner, MK 2014, 'Epigenetics and transgenerational inheritance in domesticated farm animals', Journal of Animal Science and Biotechnology, vol. 5, no. 1, pp. 48. doi: 10.1186/20491891-5-48.

Frésard, L, Morisson, M, Brun, JM, Collin, A, Pain, B, Minvielle, F \& Pitel, F 2013, 'Epigenetics and phenotypic variability: some interesting insights from birds', Genetics Seletion Evolution, vol. 45, pp. 16-32. doi: 10.1186/1297-9686-45-16.

Gao, T, Zhao, MM, Zhang, L, Li, JL, Yu, LL, Lv, PA, Gao, F \& Zhou, GH 2017, 'Effects of in ovo feeding of 1 -arginine on the development of 
lymphoid organs and small intestinal imune barrier function in posthatch broiler', Animal Feed Science and Technology, vol. 225, pp. 8-19. doi: 10.1016/i.anifeedsci.2017.01.004.

Geiman, TM \& Muegge, K 2010, 'DNA Methylation in early development', Molecular Reproduction and Development, vol. 77, no. 2, pp. 105-113. doi: 10.1002/mrd.21118.

Goddard, ME \& Whitelaw, E 2014, 'The use of epigenetic phenomena for the improvement of sheep and cattle', Frontiers in Genetics, vol. 5, pp. 247. doi: 10.3389/fgene.2014.00247

González-Recio, O 2012, 'Epigenetics: a new challenge in the post-genomic era of livestock', Frontiers in Genetics, vol. 2, pp. 106 doi: 10.3389/fgene.2011.00106.

González-Recio, O, Toro, MA \& Bach, A 2015, 'Past, presente, and future of epigenetics applied to livestock breeding', Frontiers in Genetics, vol. 6, pp. 305. doi: 10.3389/fgene.2015.00305.

Haberland, M, Haberland, M, Montgomery, RL \& Olson, EN 2009, 'The many roles of histone deacetylases in development and physiology: implications for disease and therapy', Nature Reviews Genetics, vol. 10, no. 1, pp. 32-42. doi: $10.1038 / \mathrm{nrg} 2485$.

Heard, E \& Martienssen, RA 2014, 'Transgenerational epigenetic inheritance: myths and mechanisms', Cell, vol. 157, no.1, pp. 95-109. doi: 10.1016/j.cell.2014.02.045.

Hemberger, M, Dean, W \& Reik, W 2009, 'Epigenetic dynamics of stem lineage commitment: digging Waddington's canal', Nature Reviews Molecular Cell Biology, vol. 10, pp. 526-537. doi: 10.1038/nrm2727.

Hu, J \& Barret, RDH 2017. 'Epigenetics in natural animal populations', Journal of Animal Evolutionary Biology, vol. 30, no. 9, pp. 16121632. doi: 10.1111 /jeb. 13130

Ibeagha-Awemu, EM \& Zhao, X 2015, 'Epigenetic marks: regulators of livestock phenotypes and conceivable sources of missing variation in livestock improvement programs', Frontiers in Genetics, vol. 6, pp 302. doi: 10.3389/fgene.2015.00302.

Iqbal, K, Tran, DA, Li, AX, Warden, C, Bai, AY, Singh, P, Wu, X, Pfeifer, GP \& Szabó, PE 2015, 'Epigenome reprogramming in the mammalian germline corrects deleterious effects of endocrine disruptors globally and at imprinted genes', Genome Biology, vol. 16, pp. 59. doi: 10.1186/s13059-015-0619-z.

Jablonka, E \& Raz, G 2009, 'Transgenerational epigenetic inheritance: prevalence, mechanisms, and implications for the study of heredity and evolution', The Quarterly review of biology, vol. 84, no. 2, pp. 131-176. doi: 10.1086/598822

Jammes, H, Junien, C \& Chavatte-Palmer, P 2010, 'Epigenetic control of development and expression of quantitative traits', Reproduction, Fertility and Development, vol. 23, no.1, pp. 64-74. doi: 10.1071/ RD10259.

Johannes, F \& Colomé-Tatché, M 2011 , 'Quantitative epigenetics through epigenomic perturbation of isogenic lines', Genetics, vol. 188, no. 1 pp. 215-227. doi: 10.1534/genetics. 111.127118

Kaminen-Ahola, N, Ahola, A, Maga, M, Mallitt, K, Fahey, P, Cox, TC, Whitelaw, E \& Chong, S 2010, 'Maternal etanol consumption alters the epigenotype and the phenotype of offspring in a mouse model', Plos Genetics, vol. 6, no. 1. doi: 10.1371/journal.pgen. 1000811.

Kim, JK, Samaranayake, M \& Pradhan, S 2009, 'Epigenetic mechanisms in mammals', Cellular and molecular life sciences, vol. 66, no. 4, pp. 596-612. doi: 10.1007/s00018-008-8432-4.

Legube, G \& Trouche, D 2003, 'Regulating histone acetyltransferases and deacetylases', Embo Reports, vol. 4, no. 10, pp. 944-947. doi: 10.1038/sj.embor.embor941

Leurox, S, Gourichon, D, Leterrier, C, Labrune, Y, Coustham, V, Rivière, S, Zerial, T, Coville, J, Morrison, M, Minvielle, F \& Pitel, F 2017, 'Embryonic environment and transgenerational effects in quail', Genetics Selection Evolution, vol. 49. doi: 10.1186/s12711-017-0292-7.

Li, S, Zhu, Y, Zhi, L, Han, X, Shen, J, Liu, Y, Yao, J \& Yang, X 2016, 'DNA Methylation Variation Trends during the Embryonic Development of Chicken', Plos One, vol. 11, no. 7. doi: 10.1371/journal.pone.0159230.

Lopes, MS, Bastiaansen, JW, Janss, L, Knol, EF \& Bovenhuis, H 2015, 'Estimation of additive, dominance, and imprinting genetic variance using genomic data', G3: Genes| Genomes| Genetics, vol. 5, no. 12, pp. 2629-2637. doi: 10.1534/g3.115.019513.

Martínez, D, Pentinat, T, Ribó, S, Daviaud, D, Bloks, VW, Cebrià, J, Villalmanzo, N, Kalko, SG, Ramón-Krauel, M, Díaz, R, Plosch, T, Tost, J, Jiménez-Chillarón, JC 2014, 'In útero undernutrition in male mice programs liver lipid metabolismo in the second-generation offspring involving altered Lxra DNA methylation', Cell Metabolism, vol. 19, no. 6, pp. 941-951. doi: 10.1016/i. cmet.2014.03.026.

Morison, IM, Ramsay, JP \& Spencer, HG 2005, 'A censos of mammalian imprinting', Trends in Genetics, vol. 21, no. 8, pp. 457-465. doi: 10.1016/j.tig.2005.06.008.

Paiva, JT, Resende, MDV, Resende, RT, Oliveira, HR, Silva, HT, Caetano, GC, Lopes, OS \& Silva, FF 2018a, 'Transgenerational epigenetic variance for body weight in meat quails', Journal of Animal Breeding and Genetics, vol. 135, no. 3, pp. 178-185. doi: $10.1111 /$ jbg. 12329

Paiva, JT, Resende, MDV, Resende, RT, Oliveira, HR, Silva, HT, Caetano, GC, Lopes, OS \& Silva, FF 2018b, 'A note on transgenerational epigenetics affecting egg quality traits in meat-type quail', British Poultry Science. doi: 10.1080/00071668.2018.1514582.

O'Doherty, AM, MacHugh, DE, Spllane, C \& Magee, DA 2015, 'Genomic imprinting effects on complex traits in domesticated animal species', Frontiers in Genetics, vol. 6, pp. 156. doi: 10.3389/ fgene.2015.00156.

Reik, W \& Walter, J 2001, 'Genomic imprinting: parental influence on the genome', Nature Reviews Genetics, vol. 2, pp. 21-32. doi: $10.1038 / 35047554$

Rothstein, MA, Harrell, HL \& Marchant, GE 2017, 'Transgenerational epigenetics and environmental justice', Environmental Epigenetics, vol. 3, no. 3, pp. 1-12. doi: 10.1093/eep/dvx011.

Sinclair, KD, Rutheford, KM, Wallace, JM, Bramed, JM, Stoger, R, Alberio, R, Sweetman, D, Gardner, DS, Perry, VE, Adam, CL, Ashworth, CJ, Robinson, JE \& Dwyer, CM 2016, 'Epigenetics and developmental programming of welfare and production traits in farm animals', Reproduction, Fertility and Development, vol. 28, pp. 1443-1478. doi: 10.1071/RD16102.

Skinner, MK 2011, 'Environmental epigenetic transgenerational inheritance and somatic epigenetic mitotic stability', Epigenetics, vol. 6, no. 7, pp. 838-842

Strathdee, D, Whitelaw, CB \& Clark, AJ 2008, 'Distal transgene insertion affects $\mathrm{CpG}$ island maintenance during differentiation', The Journal of Biological Chemistry, vol. 283, no. 17, pp. 11509-11515. doi: 10.1074/jbc.M709805200.

Suzuki, MM \& Bird, A 2008, 'DNA methylation landscapes: provocative insights from epigenomics', Nature Reviews Genetics, vol. 9, no. 6, pp. 465-476. doi:10.1038/nrg2341

Szyf, M 2015, Nongenetic inheritance and transgenerational epigenetics', Trends in Molecular Medicine, vol. 21, no. 2, pp. 134-44. doi: 10.1016/i.molmed.2014.12.004.

Tal, O, Kisdi, E \& Jablonka, E 2010, 'Epigenetic contribution to covariance between relatives', Genetics, vol. 184, no. 4, pp. 1037-1050. doi: 10.1534/genetics. 109.112466.

Triantaphyllopoulos, KA, Ikonomopoulos, I \& Bannister, AJ 2016, 'Epigenetics and inheritance of phenotype variation in livestock', Epigenetics Chromatin, vol. 9, pp. 31. doi: 10.1186/s13072016-0081-5.

Varona, L, Munilla, S, Mouresan, EF, Gonzalez-Rodriguez, A, Moreno, C \& Altarriba, J 2015, 'A bayesian model for the analysis of transgenerational epigenetic variation', G3: Genes| Genomes| Genetics, vol. 5, no. 4, pp. 477-485. doi: 10.1534/g3.115.016725. Verhoeven, KJF, Vonholdt, BM \& Sork, VL 2016, 'Epigenetics in ecology and evolution: What we know and what we need to know', Molecular Ecology, vol. 25, pp. 1631-1638. doi: 10.1111/mec.13617. 
Waddington, $\mathrm{CH}$ 1942, 'The epigenotype', Endeavour, vol 41, no. 1, pp. 18-20. doi: 10.1093/ije/dyr184.

Weaver, ICG, Cervoni, N, Champagne, FA, D'Alessio, AC, Sharma, S, Seckl, JR, Dymov, S, Szyf, M \& Meaney, MJ 2004, 'Epigenetic programming by maternal behavior', Nature Neuroscience, vol. 7, pp. 847-854. doi:10.1038/nn1276.
Youngson, NA \& Whitelaw, E 2008, 'Transgenerational epigenetic effects', Annual Review of Genomics and Human Genetics, vol. 9, pp. 233-257. doi: 10.1146/annurev.genom.9.081307.164445.

Zentner, GE \& Henikoff, S 2013, 'Regulation of nucleosome dynamics by histone modifications', Nature Structural e Molecular Biology, vol. 20, pp. 259-266. doi:10.1038/nsmb.2470. 